\title{
Article \\ Study on Damage Constitutive Model of Rock under Freeze-Thaw-Confining Pressure-Acid Erosion
}

\author{
Youliang Chen ${ }^{1,2}$, Peng Xiao ${ }^{1, *}$, Xi Du ${ }^{1,3}$, Suran Wang ${ }^{4}\left(\mathbb{D}\right.$, Tomas Manuel Fernandez-Steeger ${ }^{5}$ and Rafig Azzam ${ }^{2}$ \\ 1 Department of Civil Engineering, School of Environment and Architecture, University of Shanghai for \\ Science and Technology, Shanghai 200093, China; ylchen@usst.edu.cn (Y.C.); xi.du@unsw.edu.au (X.D.) \\ 2 Department of Engineering Geology and Hydrogeology, RWTH Aachen University, \\ 52064 Aachen, Germany; azzam@lih.rwth-aachen.de \\ 3 School of Civil and Environmental Engineering, University of New South Wales, Sydney 2052, Australia \\ 4 Department of Underground Architecture and Engineering, Tongji University, Shanghai 200093, China; \\ wangsuran@tongji.edu.cn \\ 5 Department of Engineering Geology, Institute of Applied Geosciences, Faculty VI Planning \\ Building Environment, Technische Universität Berlin, 10587 Berlin, Germany; fernandez-steeger@tu-berlin.de \\ * Correspondence: 193791881@st.usst.edu.cn
}

Citation: Chen, Y.; Xiao, P.; Du, X.; Wang, S.; Fernandez-Steeger, T.M.; Azzam, R. Study on Damage Constitutive Model of Rock under Freeze-Thaw-Confining PressureAcid Erosion. Appl. Sci. 2021, 11, 9431. https://doi.org/10.3390/ app11209431

Academic Editor: Roberto Tomás

Received: 26 September 2021

Accepted: 6 October 2021

Published: 11 October 2021

Publisher's Note: MDPI stays neutral with regard to jurisdictional claims in published maps and institutional affiliations.

Copyright: (c) 2021 by the authors. Licensee MDPI, Basel, Switzerland. This article is an open access article distributed under the terms and conditions of the Creative Commons Attribution (CC BY) license (https:// creativecommons.org/licenses/by/ $4.0 /)$.

\begin{abstract}
Aiming at the acid-etched freeze-thaw rock for geotechnical engineering in cold regions, chemical damage variables, freeze-thaw damage variables, and force damage variables were introduced to define the degree of degradation of rock materials, the law of damage evolution, the total damage variable of acid-corroded rock under the coupling action of freeze-thaw and confining pressure was deduced. The continuous damage mechanics theory was adopted to derive the damage evolution equation and constitutive model of acid-eroded rock under the coupling action of freeze-thaw and confining pressure. The theoretical derivation method was used to obtain the required model parameter expressions. Finally, the model's rationality and accuracy were verified by the triaxial compression test data of frozen-thawed rocks. Comparing the test curve's peak point with the peak point of the model theoretical curve, the results show that the two are in suitable agreement. The damage constitutive model can better reflect the stress-strain peak characteristics of rock during triaxial compression, verifying the rationality and reliability of the model and the method for determining the model parameters. The model extends the damage model of rock under the coupling action of freeze-thaw and confining pressure in the chemical environment and further reveals the damage mechanism and failure law of acid-corroded rock under the coupling action of freeze-thaw and confining pressure.
\end{abstract}

Keywords: rock mechanics; acid corrosion; freeze-thaw and confining pressure; coupling effect; damage evolution; constitutive model

\section{Introduction}

In the construction process of cold region projects, more complex rock engineering problems have been encountered. Many large cold region projects involve rock freezing problems, such as the Qinghai-Tibet Railway and border railways, the West-East Gas Pipeline Project, the South-to-North Water Diversion Project, and numerous tunnel projects in the central and western regions of China, etc. In the construction of geotechnical engineering in such areas, the most severe problem is the disaster caused by the freezethaw cycles. Simultaneously, with the further development of China's modern industry, the consumption of fossil fuels such as oil, natural gas, and coal is increasing, and the amount of polluting gases emitted from the atmosphere is rising sharply, which leads to the worsening of environmental pollution. The problem of acid rain following global warming has become a global environmental problem of great concern, and the resulting environmental problems cause serious engineering losses [1]. With the introduction of 
infrastructure construction such as the Sichuan-Tibet Railway and border railways, the "14th Five-Year Plan's" key projects, ensuring the safety of projects in cold regions has become the primary issue. The degradation law and damage mechanism of acid-etched rock under the coupling action of freeze-thaw and confining pressure have important practical significance for constructing these critical projects.

In recent years, research on the influence of acidic environment and freeze-thaw cycles on the physical and mechanical properties of rocks has attracted many scholars' attention, which has made great progress and fruitful results. Several scholars have carried out related studies on the effects of chemical solutions on different aspects of rocks, such as rock mineral composition, rock strength, Young's modulus, porosity, etc., and determined the effects of chemical solutions on the physical and mechanical properties of rock materials [2-9]. Some scholars have also studied the effects of freeze-thaw cycles on various aspects of rock, such as the effects of freeze-thaw cycle temperature, freeze-thaw cycles, initial water content, etc., on different aspects of rock damage [10-19]. However, the effect of rock on its mechanical properties under the action of freeze-thaw cycles and chemical solutions alone and the actual interaction results between the two are very different. In recent years, some scholars have also conducted research on rocks' physical and mechanical properties under the coupling effect of chemical solutions and freeze-thaw [20-27]. Using the theory of continuous damage mechanics and introducing freeze-thaw damage variables, the damage evolution equation and constitutive model of rock under freeze-thaw action are derived and established [28-33]. A uniaxial compression test was carried out for the rock immersed in the chemical solution, the chemical damage mechanism was analyzed, and the damage constitutive model was established [4,34]. The damage evolution model of rock under the coupled chemical-freeze-thaw action is constructed [35,36]. In order to study the damage evolution law of prefabricated cracked red sandstone samples under uniaxial cyclic compression, physical tests were carried out. Through the fitting analysis of the damage evolution equation, it is proved that the damage variable method is suitable to describe the damage evolution characteristics of fractured sandstone [37]. The effects of freeze-thaw temperature and cycle times on the physical and mechanical properties of marble and the mechanical properties and damage characteristics of red sandstone under freeze-thaw and load were studied [38,39].

The research mentioned above work has laid a suitable foundation for the correct understanding of changes in rock mechanical properties and damage laws under acidic environments and freeze-thaw cycles. However, there are still some shortcomings, mainly in the following three points: (1) the current research results mainly focus on the effects of chemical solutions and freeze-thaw cycles on the macroscopic mechanical properties of rocks; (2) there are few studies on the mechanical properties of rock damage through the establishment of freeze-thaw damage constitutive models, and most of them do not consider the effect of confining pressure and are limited to unidirectional stress; (3) there is a lack of research on constitutive models of acid-corroded rocks, and research on freezethaw damage models of acid-corroded rocks is rare. Given the above problems, further exploration is needed. Because of this, based on previous studies, this paper introduces chemical damage variables, freeze-thaw damage variables, and force damage variables based on the Weibull distribution. The microelement strength of the rock sample obeys two parameters and adopts the theory of continuous damage mechanics. Taking the D-P criterion as rock strength criteria, and based on the Lemaitre strain equivalence assumption, the damage evolution equation and constitutive model of rock under the combined action of chemical-freeze-thawing-load were established. Then, the model was verified by comparison with the test curve. The damage model of the coupling of freezethaw and confining pressure under chemical corrosion was expanded, and the damage mechanism and failure law of acid-etched rock under the coupling of freeze-thaw and confining pressure were further revealed. 


\section{Establishment of a Constitutive Model for Damage of Acid-Etched Rock under the Coupling Effect of Freezing-Thawing and Confining Pressure}

\subsection{Determination of Chemical Corrosion Damage Variables}

Yang et al. [40] defined a damage variable based on the CT (computer tomography) number of rocks:

$$
D=-\frac{1}{\mathrm{~m}_{0}^{2}} \frac{\Delta \rho}{\rho_{\mathrm{r}}}
$$

where: $\mathrm{m}_{0}$ is the spatial resolution of the CT machine; $\rho_{\mathrm{r}}$ is the density of the rock in the undamaged state; $\Delta \rho$ is the change in density during the evolution of rock damage.

Li et al. [9] combined with Yang et al. [41] based on the damage variable of rock CT number to derive the damage variable of acid-corroded sandstone:

$$
\begin{gathered}
D_{\mathrm{C}}=\frac{1}{2}\left(D_{\mathrm{C} 1}+D_{\mathrm{C} 2}\right)=1-\frac{E\left(\rho_{1}\right)+E\left(\rho_{2}\right)}{2 \rho_{0}} \\
E(\rho)=\frac{1000+H}{1000+H_{\mathrm{r}}} \rho_{\mathrm{r}}
\end{gathered}
$$

From Equations (2) and (3), the damage variable expression of acid-corroded sandstone based on rock CT number can be obtained:

$$
D_{\mathrm{C}}=1-\frac{\rho_{\mathrm{r}}\left(2000+H_{1}+H_{2}\right)}{2 \rho_{0}\left(1000+H_{\mathrm{r}}\right)}
$$

where: $\rho_{\mathrm{r}}$ is the density of the sandstone matrix material $\left(\mathrm{g} / \mathrm{cm}^{3}\right) ; \rho_{0}$ is the density of the undamaged sandstone $\left(\mathrm{g} / \mathrm{cm}^{3}\right) ; H_{1}, H_{2}, H_{\mathrm{r}}$ are the $\mathrm{CT}$ numbers of the sandstone in the corroded area, the uncorroded area, and the sandstone matrix material, respectively.

\subsection{Determination of Freeze-Thaw Damage Variables}

Under the action of the freeze-thaw cycle, defects such as initial microvoids and pores inside the rock material will continue to expand or even crack, causing freeze-thaw damage to the rock. According to the macro-damage mechanics principle, the macro-mechanical effect of the micro-defects in rock can be reflected by the change of the elastic modulus [42]. Therefore, the elastic modulus of the rock during the freeze-thaw cycles can be used as the benchmark for measuring the internal damage of the rock, namely

$$
D_{\mathrm{n}}=1-\frac{E_{\mathrm{n}}}{E_{0}}
$$

where: $D_{\mathrm{n}}$ is the rock freeze-thaw damage variable, $E_{\mathrm{n}}$ is the elastic modulus of the rock after $n$ cycles of freezing and thawing, and $E_{0}$ is the initial elastic modulus of the rock before the freeze-thaw cycles.

\subsection{Determination of Force Damage Variables}

Because rock is a non-uniform material with a large number of randomly distributed pores, the damage process of rock is the process of the initiation, development, and accumulation of internal pores under external load action, which is directly related to the number of damaged cells. The destruction of micro-elements is generally random. The damage variable $D$ is defined as the ratio of the number of damaged cells $n$ under a certain stress level to the total number of cells $N$ in the initial state, namely

$$
D=\frac{n}{N}
$$

Under the action of external load, the failure of the rock element is random. According to the Krajicinovic model, the damage variable is the failure probability $P$ of the element [43]. 
If the probability density function of the element failure is $\phi(x)$, then $P$ is the cumulative distribution function of $F$, namely

$$
D=P=\int_{0}^{F} \phi(x) d x
$$

Studies have shown that when establishing a statistical constitutive model of rock damage, the study of the damage evolution characteristics during rock failure is based on the assumption that the strength of the rock's microelement obeys the normal or Weibull distribution. Compared with the normal distribution, the Weibull distribution is a less conservative type of distribution, which reflects the distribution of random variables more truly to a certain extent. So, this article assumes that the strength of the rock element obeys the Weibull distribution, and its probability density function is:

$$
\phi(F)=\frac{m}{F_{0}}\left(\frac{F}{F_{0}}\right)^{m-1} \exp \left[-\left(\frac{F}{F_{0}}\right)^{m}\right]
$$

where: $F$ represents the intensity of the infinitesimal element, $m$ and $F_{0}$ are the parameters of the Weibull distribution.

From Equation (7), the damage variable of the rock under load is

$$
D=\int_{0}^{F} \phi(x) d x=1-\exp \left[-\left(\frac{F}{F_{0}}\right)^{m}\right]
$$

2.4. Determination of the Total Damage Variable of Acid-Etched Rock under the Coupling Effect of Freezing-Thawing and Confining Pressure

Because rocks exhibit different damage characteristics under chemical corrosion, freeze-thaw cycles, and loads, acid-corroded rocks' total damage under the coupling of freeze-thaw and confining pressure is not a simple superposition of their respective damages. Suppose that the volume of the defective material expresses the damage of the rock under the two states of freeze-thaw and load, that is, the ratio of the defect volume to the total volume of the material, assuming that the effective volumes of undamaged rock, freeze-thaw damaged rock and freeze-thaw-confining pressure coupling effect damage rock are $V_{0}, V_{1}$, and $V_{2}$, respectively, then

$$
\begin{aligned}
& D_{\mathrm{n}}=1-\frac{V_{1}}{V_{0}} \\
& D_{\mathrm{m}}=1-\frac{V_{2}}{V_{1}}
\end{aligned}
$$

Combining Equations (10) and (11) can obtain the total rock damage variable under the coupling of freeze-thaw and confining pressure

$$
D_{S}=D_{\mathrm{m}}+D_{\mathrm{n}}-D_{\mathrm{m}} D_{\mathrm{n}}
$$

where: $D_{S}$ is the total rock damage variable under the coupling effect of freeze-thaw and confining pressure.

The essence of rock freeze-thaw damage is that the volume expansion force generated by volume expansion acts on the initial microvoids and pores in the rock and brings certain tensile stress to the pores, causing the microvoids and pores to expand and even crack. Rock will also cause grain slip and dislocation under load. The damage induced by grain slip and dislocation under load and the damage caused by freezing and thawing interact and couple with each other, causing more complicated changes in the physical and mechanical properties of the rock and the damage mechanism. Equation (12) shows that under the 
combined action of freeze-thaw and load, the total damage of the rock will be aggravated and show obvious nonlinear characteristics, but the coupling effect of freeze-thaw and load will weaken the total damage of the rock.

From the above analysis, the total damage variables of acid-etched rock under the coupling effect of freezing-thawing and confining pressure can be obtained:

$$
D=D_{\mathrm{C}}+D_{S}-D_{\mathrm{C}} D_{S}=D_{\mathrm{C}}+D_{\mathrm{n}}+D_{\mathrm{m}}-D_{\mathrm{n}} D_{\mathrm{m}}-D_{\mathrm{C}} D_{\mathrm{n}}-D_{\mathrm{C}} D_{\mathrm{m}}+D_{\mathrm{C}} D_{\mathrm{n}} D_{\mathrm{m}}
$$

Substituting Formulas (4), (5) and (9) into Formula (13) can obtain the total damage variable of acid-etched rock under the coupling effect of freezing-thawing and confining pressure:

$$
D=1-\frac{\rho_{\mathrm{r}}\left(2000+H_{1}+H_{2}\right)}{2 \rho_{0}\left(1000+H_{\mathrm{r}}\right)} \frac{E_{\mathrm{n}}}{E_{0}} \exp \left[-\left(\frac{F}{F_{0}}\right)^{m}\right]
$$

\subsection{Determination of Rock Microelement Strength under Confining Pressure}

The failure of rock samples under load is basically a shear failure. The criteria for assuming the failure of rock samples are:

$$
f\left(\sigma^{*}\right)=k_{0}
$$

where: $\sigma^{*}$ is the effective stress of the rock and $k_{0}$ is a constant.

Because the Drucker-Prager (D-P) criterion considers the influence of the intermediate principal stress and the hydrostatic pressure, which overcomes the defect that the MohrCoulomb criterion does not consider the influence of the intermediate principal stress on the rock strength. Therefore, the D-P criterion is more suitable for geotechnical materials and has a wider application range. According to the D-P failure criterion, the rock element strength $F$ is

$$
F=f\left(\sigma^{*}\right)=\alpha I_{1}+\sqrt{J_{2}}
$$

where: $\alpha$ is the strength parameter of the rock element, $I_{1}$ and $J_{2}$ are the first invariant of stress and the second invariant of deviator stress, and $\alpha, I_{1}$, and $J_{2}$ are

$$
\begin{gathered}
\alpha=\frac{\sin \varphi}{\sqrt{9+3 \sin ^{2} \varphi}} \\
I_{1}=\sigma_{1}^{*}+\sigma_{2}^{*}+\sigma_{3}^{*} \\
J_{2}=\frac{\left(\sigma_{1}^{*}-\sigma_{2}^{*}\right)^{2}+\left(\sigma_{2}^{*}-\sigma_{3}^{*}\right)^{2}+\left(\sigma_{3}^{*}-\sigma_{1}^{*}\right)^{2}}{6},
\end{gathered}
$$

respectively.

In formula (17), $\varphi$ is the friction angle of the rock.

According to the generalized Hooke's law and the principle of strain equivalence, and $\sigma_{2}=\sigma_{3}$, there are

$$
\left.\begin{array}{c}
\varepsilon_{1}=\left(\sigma_{1}^{*}-2 v \sigma_{3}^{*}\right) / E \\
\sigma_{1}^{*}=\frac{\sigma_{1}}{1-D} \\
\sigma_{2}^{*}=\frac{\sigma_{2}}{1-D} \\
\sigma_{3}^{*}=\frac{\sigma_{3}}{1-D} \\
1-D=\frac{\left(\sigma_{1}-2 v \sigma_{3}\right)}{E \varepsilon_{1}}
\end{array}\right\}
$$

Express the above $I_{1}$ and $J_{2}$ with the nominal stress $\sigma_{i}$, namely

$$
\begin{gathered}
I_{1}=E \varepsilon_{1}\left(\sigma_{1}+2 \sigma_{3}\right) /\left(\sigma_{1}-2 v \sigma_{3}\right) \\
\sqrt{J_{2}}=E \varepsilon_{1}\left(\sigma_{1}-\sigma_{3}\right) / \sqrt{3}\left(\sigma_{1}-2 v \sigma_{3}\right)
\end{gathered}
$$


Substituting Formulas (17), (21) and (22) into Formula (16) can obtain the rock element strength $F$ under confining pressure, namely

$$
F=f\left(\sigma^{*}\right)=\alpha I_{1}+\sqrt{J_{2}}=\frac{E \varepsilon_{1}\left[\sin \varphi\left(\sigma_{1}+2 \sigma_{3}\right)+\sqrt{3+\sin ^{2} \varphi}\left(\sigma_{1}-\sigma_{3}\right)\right]}{\sqrt{9+3 \sin ^{2} \varphi}\left(\sigma_{1}-2 v \sigma_{3}\right)}
$$

2.6. Damage Evolution Equation of Acid-Etched Rock under the Coupling Effect of Freeze-Thaw and Confining Pressure

Substituting Equation (23) into Equation (14), the damage evolution equation of acidetched rock under the coupling of freezing-thawing and confining pressure can be obtained, namely

$$
D=1-\frac{\rho_{\mathrm{r}}\left(2000+H_{1}+H_{2}\right)}{2 \rho_{0}\left(1000+H_{\mathrm{r}}\right)} \frac{E_{\mathrm{n}}}{E_{0}} \exp \left\{-\left\{\frac{E_{\mathrm{n}} \varepsilon_{1}\left[\sin \varphi\left(\sigma_{1}+2 \sigma_{3}\right)+\sqrt{3+\sin ^{2} \varphi}\left(\sigma_{1}-\sigma_{3}\right)\right]}{F_{0} \sqrt{9+3 \sin ^{2} \varphi}\left(\sigma_{1}-2 v \sigma_{3}\right)}\right\}\right\}
$$

\subsection{Damage Constitutive Model of Acid-Etched Rock under the Coupling Effect of} Freezing-Thawing and Confining Pressure

According to the Lemaitre strain equivalence principle and the concept of effective stress, the strain produced by the damaged rock under the nominal stress is equivalent to the effective strain produced by the undamaged rock under the effective stress (the nominal stress is the stress measured by the test). Then the rock damage constitutive relationship can be established as follows:

$$
\sigma_{i}^{*}=\frac{\sigma_{i}}{1-D} ; i=1,2,3
$$

where: $\sigma_{i}^{*}$ is the effective stress of the rock, $\sigma_{i}$ is the nominal stress of the rock, and $D$ is the damage variable of the rock. According to the generalized Hooke's law

$$
\varepsilon_{i}^{*}=\left[\sigma_{i}^{*}-v\left(\sigma_{j}^{*}+\sigma_{k}^{*}\right)\right] / E_{\mathrm{n}}
$$

where: $(i, j, k)$ is $(1,2,3), E_{\mathrm{n}}$ is the elastic modulus of the rock after $\mathrm{n}$ cycles of freezing and thawing, $v$ is Poisson's ratio, $\varepsilon_{i}^{*}$ is the effective strain corresponding to the effective stress $\sigma_{i}^{*}$.

According to the deformation coordination conditions:

$$
\varepsilon_{i}^{*}=\varepsilon_{i}
$$

Then the constitutive relationship of rock damage can be obtained from Equations (25)-(27):

$$
\sigma_{1}=E_{\mathrm{n}} \varepsilon_{1}(1-D)+v\left(\sigma_{2}+\sigma_{3}\right)
$$

According to the triaxial compression test of the rock, the loading sequence of the conventional triaxial compression test of the rock is to apply the confining pressure through hydraulic oil first and then load the axial pressure when the confining pressure stabilizes to a predetermined value. Therefore, before the axial pressure is applied, the rock will produce initial axial strain under the action of the confining pressure, so the axial deflection stress $\sigma_{1 \mathrm{t}}$ recorded in the test is the difference between the axial stress $\sigma_{1}$ and the confining pressure $\sigma_{3}$, namely

$$
\sigma_{1 \mathrm{t}}=\sigma_{1}-\sigma_{3}
$$


Under the action of confining pressure, the initial axial strain produced by the rock is

$$
\varepsilon_{10}=\frac{1-2 v}{E_{\mathrm{n}}} \sigma_{3}
$$

Since the test results do not include the initial axial strain generated before the axial pressure is applied, the actual axial strain $\varepsilon_{1}$ is the sum of the measured axial strain $\varepsilon_{1 \mathrm{t}}$ and the initial axial strain $\varepsilon_{10}$, namely

$$
\varepsilon_{1}=\varepsilon_{1 \mathrm{t}}+\varepsilon_{10}
$$

Substituting Formulas (24) and (29)-(31) into Formula (28), the damage constitutive model of acid-etched rock under the coupling effect of freezing and thawing and confining pressure can be obtained:

$$
\begin{aligned}
\sigma_{1 \mathrm{t}}=\left[E_{\mathrm{n}} \varepsilon_{1 \mathrm{t}}+(1-2 v) \sigma_{3}\right] \frac{\rho_{\mathrm{r}}\left(2000+H_{1}+H_{2}\right)}{2 \rho_{0}\left(1000+H_{\mathrm{r}}\right)} \frac{E_{\mathrm{n}}}{E_{0}} \exp \left\{-\left\{\frac{\left[E_{\mathrm{n}} \varepsilon_{1 \mathrm{t}}+(1-2 v) \sigma_{3}\right]\left[\left(\sigma_{1 \mathrm{t}}+3 \sigma_{3}\right) \sin \varphi+\sigma_{1 \mathrm{t}} \sqrt{3+\sin ^{2} \varphi}\right]}{F_{0} \sqrt{9+3 \sin ^{2} \varphi\left[\sigma_{1 \mathrm{t}}+(1-2 v) \sigma_{3}\right]}}\right\}^{m}\right\} \\
+(2 v-1) \sigma_{3}
\end{aligned}
$$

\section{Determination of Model Parameters}

It can be seen from Equation (32) that the parameters that need to be determined in this model are $\rho_{\mathrm{r}}, \rho_{0}, H_{1}, H_{2}, H_{\mathrm{r}}, E_{\mathrm{n}}$, and $m, F_{0}$. For parameter $E_{\mathrm{n}}$, a second-order polynomial can be used to fit the trend of the elastic modulus with the number of freeze-thaw cycles. In contrast, for parameters $m$ and $F_{0}$, the peak point $\left(\varepsilon_{\mathrm{p}}, \sigma_{\mathrm{p}}\right)$ of the rock stress-strain curve can be used to determine, that is, the extreme value method. The specific techniques for determining model parameters are as follows:

The model parameter $\rho_{\mathrm{r}}, \rho_{0}, H_{1}, H_{2}, H_{\mathrm{r}}$ is obtained through the rock test and rock CT scan test.

The damage caused by the freeze-thaw cycle of the rock is presented in the form of freeze-thaw damage. This article defines the freeze-thaw damage variable of the rock. The degree of damage of the rock under different freeze-thaw cycles is proportional to the elastic modulus. The change in the number of freeze-thaw cycles can be used to characterize the constitutive model of rock damage. Equation (32) shows that the rock damage constitutive model is directly related to $E_{\mathrm{n}}$. Therefore, the constitutive model's applicability can be further improved only by establishing the relationship between the rock elastic modulus $E$ and the number of freeze-thaw cycles $n$. From previous studies on the mechanical properties of rock under the action of freeze-thaw cycles, it can be found that the elastic modulus of rock generally decreases with the increase in the number of freeze-thaw cycles. This changing trend can be highly fitted by polynomials. Therefore, for most rocks, a second-degree polynomial can be used to fit the trend of elastic modulus with the number of freeze-thaw cycles. That is, the expression of $E_{\mathrm{n}}$ can be expressed as:

$$
E_{\mathrm{n}}=\mathrm{a} n^{2}+\mathrm{b} n+\mathrm{c}
$$

where: $a, b$, and $c$ are all constants, which are obtained by fitting experimental data.

The peak stress $\sigma_{\mathrm{p}}$ and the corresponding peak strain $\varepsilon_{\mathrm{p}}$ of the rock under different confining pressures satisfy the following two geometric conditions:

$$
\begin{aligned}
& \varepsilon=\varepsilon_{\mathrm{p}}, \sigma_{1}=\sigma_{\mathrm{p}} \\
& \varepsilon=\varepsilon_{\mathrm{p}}, \frac{d \sigma_{1}}{d \varepsilon_{1}}=0
\end{aligned}
$$

First, substituting Formula (34) into Formula (32), we can get:

$$
\frac{\rho_{\mathrm{r}}\left(2000+H_{1}+H_{2}\right)}{2 \rho_{0}\left(1000+H_{\mathrm{r}}\right)} \frac{E_{\mathrm{n}}}{E_{0}} \exp \left[-\left(\frac{F_{\mathrm{sc}}}{F_{0}}\right)^{m}\right]=\frac{\sigma_{\mathrm{p}}+(1-2 v) \sigma_{3}}{E_{\mathrm{n}} \varepsilon_{\mathrm{p}}+(1-2 v) \sigma_{3}}
$$




$$
\begin{aligned}
& \text { Among them } \\
& F=\frac{\left[E_{\mathrm{n}} \varepsilon_{1 \mathrm{t}}+(1-2 v) \sigma_{3}\right]\left[\left(\sigma_{1 \mathrm{t}}+3 \sigma_{3}\right) \sin \varphi+\sigma_{1 \mathrm{t}} \sqrt{3+\sin ^{2} \varphi}\right]}{\sqrt{9+3 \sin ^{2} \varphi}\left[\sigma_{1 \mathrm{t}}+(1-2 v) \sigma_{3}\right]} \\
& \left.\frac{\partial \sigma_{1 \mathrm{t}}}{\partial \varepsilon_{1 \mathrm{t}}}\right|_{\substack{\sigma_{1 \mathrm{t}} \\
\varepsilon_{1 \mathrm{t}}=\sigma_{\mathrm{p}}}}=\frac{\rho_{\mathrm{r}}\left(2000+H_{1}+H_{2}\right)}{2 \rho_{0}\left(1000+H_{\mathrm{r}}\right)} \frac{E_{\mathrm{n}}}{E_{0}} \exp \left[-\left(\frac{F}{F_{0}}\right)^{m}\right]\left\{E_{\mathrm{n}}-\frac{m\left[E_{\mathrm{n}} \varepsilon_{\mathrm{p}}+(1-2 v) \sigma_{3}\right]}{F_{\mathrm{sc}}}\left(\frac{F_{\mathrm{sc}}}{F_{0}}\right)^{m} \frac{\partial F_{\mathrm{sc}}}{\partial \varepsilon_{1 \mathrm{t}}}\right\}
\end{aligned}
$$

Know from Formula (35)

$$
E_{\mathrm{n}}-\frac{m\left[E_{\mathrm{n}} \varepsilon_{\mathrm{p}}+(1-2 v) \sigma_{3}\right]}{F_{\mathrm{Sc}}}\left(\frac{F_{\mathrm{sc}}}{F_{0}}\right)^{m} \frac{\partial F_{\mathrm{Sc}}}{\partial \varepsilon_{1 \mathrm{t}}}=0
$$

Then take the partial derivative of Equation (37) to get

$$
\left.\frac{\partial F_{\mathrm{sc}}}{\partial \varepsilon_{1 \mathrm{t}}}\right|_{\begin{array}{l}
\sigma_{1 \mathrm{t}} \\
\varepsilon_{1 \mathrm{t}}=\sigma_{\mathrm{p}} \\
=\varepsilon_{\mathrm{p}}
\end{array}}=\frac{E_{\mathrm{n}}\left[\left(\sigma_{\mathrm{p}}+3 \sigma_{3}\right) \sin \varphi+\sigma_{\mathrm{p}} \sqrt{3+\sin ^{2} \varphi}\right]}{\sqrt{9+3 \sin ^{2} \varphi}\left[\sigma_{\mathrm{p}}+(1-2 v) \sigma_{3}\right]}
$$

Substituting Equation (40) into Equation (39), we can get

$$
\left(\frac{F_{\mathrm{Sc}}}{F_{0}}\right)^{m}=\frac{F_{\mathrm{sc}} \sqrt{9+3 \sin ^{2} \varphi}\left[\sigma_{\mathrm{p}}+(1-2 v) \sigma_{3}\right]}{m\left[E_{\mathrm{n}} \varepsilon_{\mathrm{p}}+(1-2 v) \sigma_{3}\right]\left[\left(\sigma_{\mathrm{p}}+3 \sigma_{3}\right) \sin \varphi+\sigma_{\mathrm{p}} \sqrt{3+\sin ^{2} \varphi}\right]}=\frac{1}{m}
$$

Comparing Equation (36), the expressions of parameters $m$ and $F_{0}$ are

$$
\begin{gathered}
m=\frac{1}{\ln \frac{E_{\mathrm{n}}}{E_{0}} \frac{\rho_{\mathrm{r}}\left(2000+H_{1}+H_{2}\right)}{2 \rho_{0}\left(1000+H_{\mathrm{r}}\right)}\left[\frac{E_{\mathrm{n}} \varepsilon_{\mathrm{p}}+(1-2 v) \sigma_{3}}{\sigma_{\mathrm{p}}+(1-2 v) \sigma_{3}}\right]} \\
F_{0}=\frac{\left[E_{\mathrm{n}} \varepsilon_{\mathrm{p}}+(1-2 v) \sigma_{3}\right]\left[\left(\sigma_{\mathrm{p}}+3 \sigma_{3}\right) \sin \varphi+\sigma_{\mathrm{p}} \sqrt{3+\sin ^{2} \varphi}\right]}{\sqrt{9+3 \sin ^{2} \varphi}\left[\sigma_{\mathrm{p}}+(1-2 v) \sigma_{3}\right]} m^{\frac{1}{m}}
\end{gathered}
$$

According to the parameter mentioned above determination method, substituting the obtained parameters $\rho_{\mathrm{r}}, \rho_{0}, H_{1}, H_{2}, H_{\mathrm{r}}, E_{\mathrm{n}}$, and $m, F_{0}$ into formula (32), the damage constitutive model of the acid-etched rock under the coupling effect of freezing-thawing and confining pressure can be obtained.

\section{Verification of Damage Statistical Constitutive Model of Rock under Triaxial Compression}

To verify the rationality and accuracy of the rock damage evolution equation, damage constitutive model, and parameter determination method constructed in this paper, related research results of red sandstone under freeze-thaw environment by Zhang et al. [44] were used to verify in this paper. The specific method is as follows:

First, conduct freeze-thaw tests with different freeze-thaw cycles (the number of freeze-thaw cycles is $0,5,10,20$, and 40 , respectively), and then subject the rock samples to 
four types of confining pressure under conventional triaxial compression test (confining pressures are $0 \mathrm{MPa}, 2 \mathrm{MPa}, 4 \mathrm{MPa}, 6 \mathrm{MPa}$, respectively) to obtain the test curve, and then compare the test curve with the theoretical curve of the model to verify the rationality and accuracy of the model. The mechanical parameters of red sandstone under different freeze-thaw cycles and different confining pressures are shown in Tables 1-5.

Table 1. Mechanical parameters of red sandstone without freeze-thaw cycle.

\begin{tabular}{cccccc}
\hline$\sigma_{3} / \mathbf{M P a}$ & $\sigma_{\mathrm{p}} / \mathbf{M P a}$ & $\varepsilon_{\mathbf{p}} / \%$ & $E / \mathrm{GPa}$ & $\boldsymbol{v}$ & $\boldsymbol{\varphi} /{ }^{\circ}$ \\
\hline 0 & 4.230 & 0.4 & 1.260 & 0.260 & 38.400 \\
2 & 14.572 & 1.1 & 1.387 & 0.258 & 38.400 \\
4 & 19.652 & 1.3 & 1.628 & 0.255 & 38.400 \\
6 & 24.866 & 1.6 & 1.649 & 0.254 & 38.400 \\
\hline
\end{tabular}

Table 2. Mechanical parameters of red sandstone under 5 freeze-thaw cycles.

\begin{tabular}{cccccc}
\hline$\sigma_{3} / \mathbf{M P a}$ & $\sigma_{\mathbf{p}} / \mathbf{M P a}$ & $\varepsilon_{\mathbf{p}} / \%$ & $E / \mathbf{G P a}$ & $v$ & $\varphi /^{\circ}$ \\
\hline 0 & 4.020 & 0.5 & 0.867 & 0.268 & 35.783 \\
2 & 13.101 & 1.1 & 1.295 & 0.259 & 35.783 \\
4 & 19.132 & 1.3 & 1.452 & 0.257 & 35.783 \\
6 & 24.347 & 1.7 & 1.565 & 0.255 & 35.783 \\
\hline
\end{tabular}

Table 3. Mechanical parameters of red sandstone under 10 freeze-thaw cycles.

\begin{tabular}{cccccc}
\hline$\sigma_{3} / \mathbf{M P a}$ & $\sigma_{\mathrm{p}} / \mathbf{M P a}$ & $\varepsilon_{\mathrm{p}} / \%$ & $E / \mathrm{GPa}$ & $\boldsymbol{v}$ & $\boldsymbol{\varphi} /^{\circ}$ \\
\hline 0 & 3.800 & 0.5 & 0.761 & 0.271 & 33.606 \\
2 & 12.701 & 1.1 & 1.156 & 0.262 & 33.606 \\
4 & 18.910 & 1.5 & 1.289 & 0.260 & 33.606 \\
6 & 23.519 & 1.9 & 1.325 & 0.259 & 33.606 \\
\hline
\end{tabular}

Table 4. Mechanical parameters of red sandstone under 20 freeze-thaw cycles.

\begin{tabular}{cccccc}
\hline$\sigma_{3} / \mathbf{M P a}$ & $\sigma_{\mathrm{p}} / \mathbf{M P a}$ & $\varepsilon_{\mathbf{p}} / \%$ & $E / \mathrm{GPa}$ & $\boldsymbol{v}$ & $\boldsymbol{\varphi} /{ }^{\circ}$ \\
\hline 0 & 3.749 & 0.6 & 0.529 & 0.279 & 30.905 \\
2 & 11.356 & 1.2 & 0.890 & 0.268 & 30.905 \\
4 & 18.100 & 1.8 & 1.066 & 0.264 & 30.905 \\
6 & 22.903 & 2.1 & 1.240 & 0.260 & 30.905 \\
\hline
\end{tabular}

Table 5. Mechanical parameters of red sandstone under 40 freeze-thaw cycles.

\begin{tabular}{cccccc}
\hline$\sigma_{3} / \mathbf{M P a}$ & $\sigma_{\mathrm{p}} / \mathbf{M P a}$ & $\varepsilon_{\mathbf{p}} / \%$ & $E / \mathrm{GPa}$ & $\boldsymbol{v}$ & $\boldsymbol{\varphi} /{ }^{\circ}$ \\
\hline 0 & 3.301 & 0.6 & 0.515 & 0.280 & 29.198 \\
2 & 10.570 & 1.5 & 0.710 & 0.277 & 29.198 \\
4 & 17.121 & 1.9 & 0.917 & 0.273 & 29.198 \\
6 & 21.274 & 2.5 & 0.932 & 0.269 & 29.198 \\
\hline
\end{tabular}

Substituting the original physical and mechanical parameters of red sandstone in Tables 1-5 into Equations (42) and (43), the Weibull distribution parameters $m$ and $F_{0}$ under different freeze-thaw cycles, and different confining pressures can be obtained, which is shown in Table 6. 
Table 6. Model calculation parameters of red sandstone under different freeze-thaw cycles and confining pressures.

\begin{tabular}{cccccc}
\hline Freeze-Thaw Times $\mathbf{n}$ & $\sigma_{3} / \mathbf{M P a}$ & $\sigma_{\mathbf{p}} / \mathbf{M P a}$ & $\varepsilon_{\mathbf{p}} / \%$ & $\boldsymbol{m}$ & $\boldsymbol{F}_{\mathbf{0}} / \mathbf{M P a}$ \\
\hline \multirow{2}{*}{0} & 0 & 4.230 & 0.4 & 2.251 & 5.581 \\
& 2 & 14.572 & 1.1 & 4.839 & 17.965 \\
& 4 & 19.652 & 1.3 & 12.601 & 22.912 \\
\multirow{2}{*}{5} & 6 & 24.866 & 1.6 & 18.821 & 27.990 \\
\hline & 0 & 4.020 & 0.5 & 1.802 & 4.579 \\
& 2 & 13.101 & 1.1 & 6.794 & 15.895 \\
& 4 & 19.132 & 1.3 & 9.635 & 20.981 \\
& 6 & 24.347 & 1.7 & 7.892 & 30.763 \\
\hline \multirow{2}{*}{10} & 0 & 3.800 & 0.5 & 2.222 & 4.104 \\
& 2 & 12.701 & 1.1 & 2.983 & 15.332 \\
& 4 & 18.910 & 1.5 & 4.055 & 23.556 \\
& 6 & 23.519 & 1.9 & 3.859 & 31.470 \\
\hline \multirow{2}{*}{20} & 0 & 3.749 & 0.6 & 2.974 & 3.396 \\
& 2 & 11.356 & 1.2 & 1.913 & 12.478 \\
& 4 & 18.100 & 1.8 & 2.188 & 23.216 \\
& 6 & 22.903 & 2.1 & 2.668 & 32.312 \\
\hline \multirow{2}{*}{40} & 0 & 3.301 & 0.6 & 0.754 & 1.559 \\
& 2 & 10.570 & 1.5 & 0.971 & 8.497 \\
& 4 & 17.121 & 1.9 & 1.786 & 20.305 \\
& 6 & 21.274 & 2.5 & 1.655 & 27.097 \\
\hline
\end{tabular}

Test Results and Analysis

Compare the peak points of the stress-strain curve under different freeze-thaw cycles and different confining pressures with the peak points of the model's theoretical curve, as shown in Figures 1 and 2 By comparing the experimental curve's peak points and the theoretical curve, the results show that the two are in suitable agreement, indicating that the established rock freeze-thaw-confining pressure coupled damage constitutive model can better reflect the stress-strain peak value of the rock during triaxial compression characteristic.
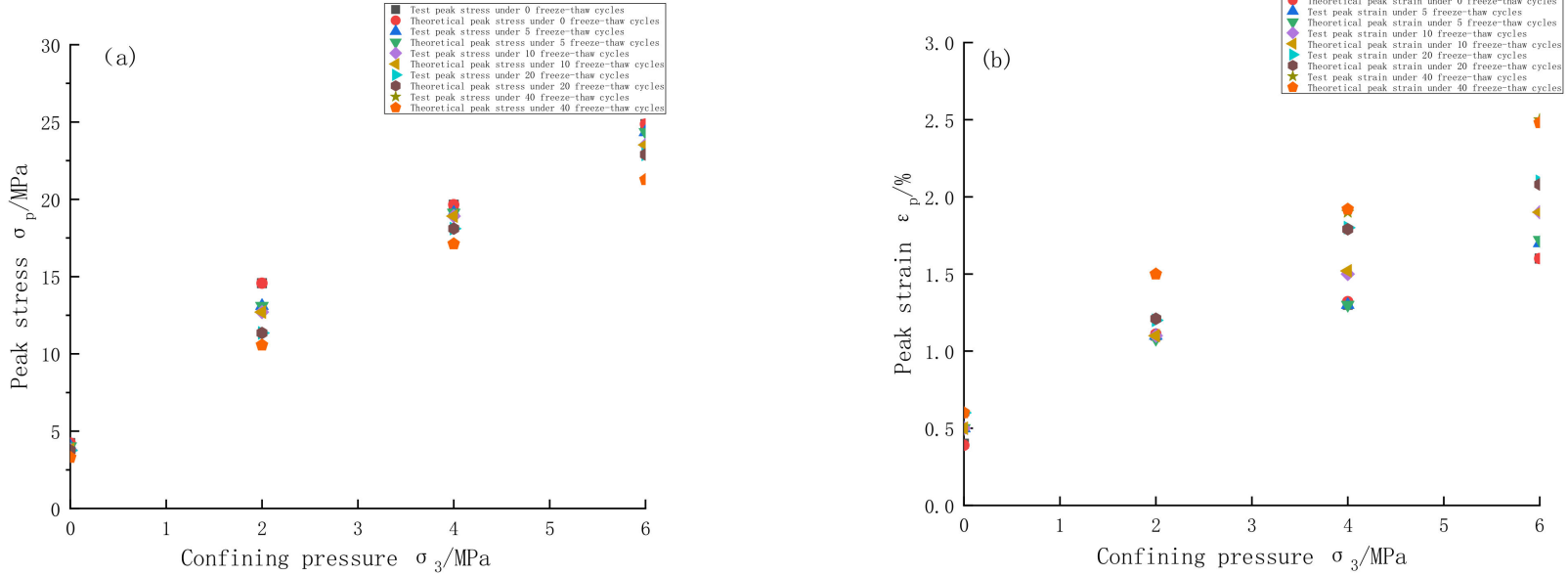

Figure 1. (a) Peak stress of different confining pressures under the same number of freeze-thaw cycles. (b) Peak strain of different confining pressures under the same number of freeze-thaw cycles. 


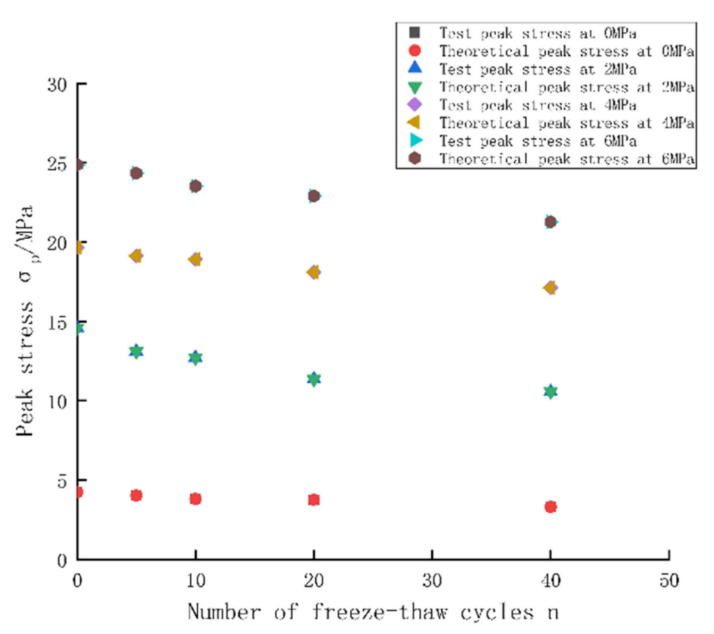

(a)

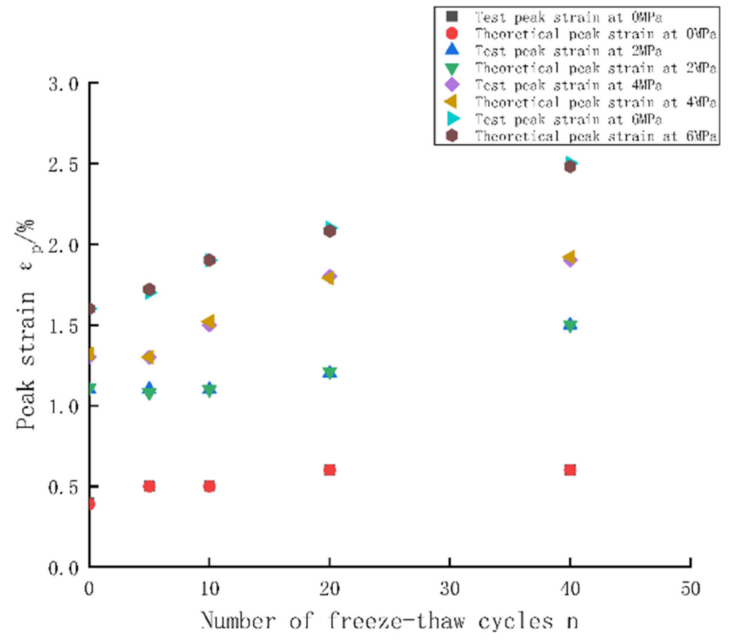

(b)

Figure 2. (a) Peak stress of different freeze-thaw cycles under the same confining pressure. (b) Peak strain of different freeze-thaw cycles under the same confining pressure.

Fit the elastic modulus of each freeze-thaw cycle number of the rock sample under the action of $0 \mathrm{MPa}$ and $6 \mathrm{MPa}$ to obtain the fitting parameters $\mathrm{a}, \mathrm{b}$, and $\mathrm{c}$, where at $0 \mathrm{MPa}$, $\mathrm{a}=9.234 \times 10^{-4} \mathrm{GPa}, \mathrm{b}=-0.054 \mathrm{GPa}, \mathrm{c}=1.203 \mathrm{GPa}$; at $6 \mathrm{MPa}, \mathrm{a}=2.298 \times 10^{-4} \mathrm{GPa}$, $\mathrm{b}=-0.027 \mathrm{GPa}, \mathrm{c}=1.649 \mathrm{GPa}$, the fitting curves are shown in Figures 3 and 4.

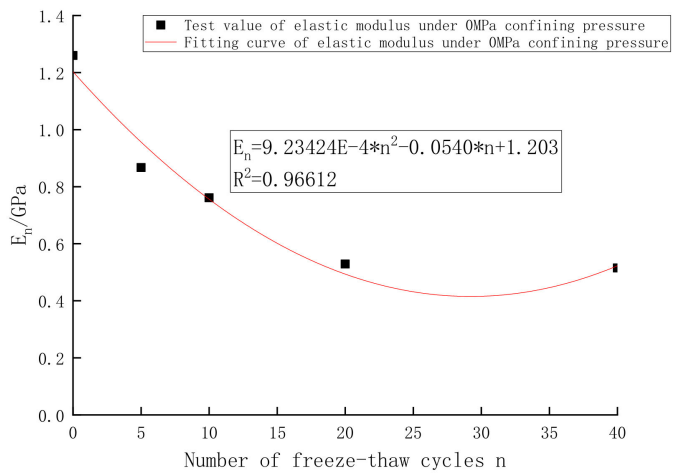

Figure 3. Fitting curve of elastic modulus under different freeze-thaw cycles under confining pressure of $0 \mathrm{MPa}$.

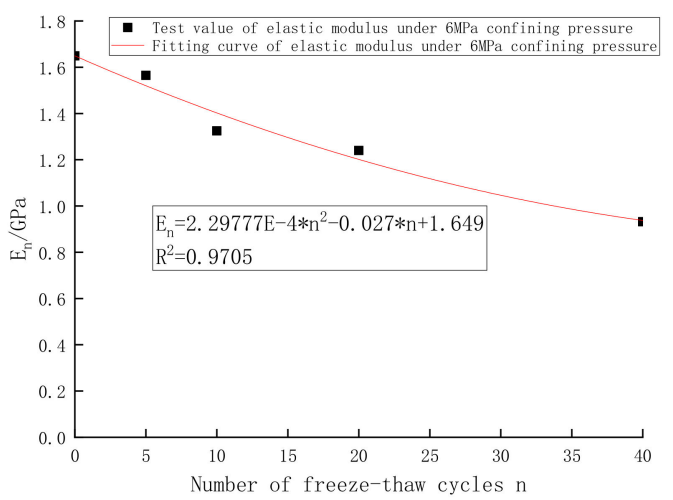

Figure 4. Fitting curve of elastic modulus under different freeze-thaw cycles under confining pressure of $6 \mathrm{MPa}$. 
It can be seen from Figures 3 and 4 that the goodness of fit $\left(R^{2}\right)$ of the red sandstone elastic modulus with the number of freeze-thaw cycles under $0 \mathrm{MPa}$ and $6 \mathrm{MPa}$ confining pressure is 0.966 and 0.971 , respectively, indicating that $6 \mathrm{MPa}$ is used the degree of fitting under the action of confining pressure is relatively high. Therefore it is more accurate to calculate with the parameters a, b, and c obtained by fitting under the action of $6 \mathrm{MPa}$, and the simulated elastic modulus of red sandstone under the action of different freeze-thaw cycles can be obtained. The combined value is shown in Table 7 .

Table 7. Fitting values of elastic modulus of red sandstone under different freeze-thaw cycles.

\begin{tabular}{ccc}
\hline $\begin{array}{c}\text { Number of Freeze-Thaw } \\
\text { Cycles n }\end{array}$ & Fitting Expression & $\begin{array}{c}\text { Elastic Modulus Fitted Value } \\
\boldsymbol{E}_{\mathbf{n}} / \mathrm{GPa}\end{array}$ \\
\hline 0 & & 1.649 \\
5 & $E_{\mathrm{n}}=2.298 \mathrm{E}-4 \times \mathrm{n}^{2}-$ & 1.520 \\
10 & $0.027 \times \mathrm{n}+1.649$ & 1.402 \\
20 & & 1.201 \\
40 & & 0.937 \\
\hline
\end{tabular}

It can be seen from Figures 1 and 2 that under the same confining pressure, the peak stress of red sandstone gradually decreases with the increase in the number of freeze-thaw cycles. Under the same number of freeze-thaw cycles, the peak stress of red sandstone increases with the growth of confining pressure. The theoretical curve can reflect the trend of rock strength and deformation with the number of freeze-thaw cycles and confining pressure, indicating that the constitutive model established in this paper, including the coupled damage evolution equation of rock freeze-thaw-confining pressure, can fully reflect the characteristics that the strength of freeze-thaw rock depends on the confining pressure.

\section{Conclusions}

By introducing chemical damage variables, freeze-thaw damage variables, and force damage variables, this paper derives the total damage variables of the acid-corroded rock under the coupling effect of freezing-thawing and confining pressure. Based on the assumption that the microelement strength of the rock obeys the Weibull distribution, adopt damage mechanics theory, D-P criterion is selected. Adopting the Lemaitre strain equivalence hypothesis, a constitutive model including freeze-thaw-confining pressure coupled damage evolution equation of acid-etched rock is established to study the damage evolution characteristics of rock failure.

(1) Comparing the theoretical curve peak point of the damage constitutive model established in this paper with the peak point of the experimental data curve, the results show that the two are in suitable agreement, indicating that the established damage constitutive model can better reflect the triaxial compression process of the rock the stress-strain peak characteristics. It has particular practical significance for geotechnical engineering construction in cold area engineering.

(2) The peak strain at the peak point of the theoretical curve of the damage constitutive model established in this paper does not change much with the number of freeze-thaw cycles, and the peak stress will fluctuate slightly with the number of freeze-thaw cycles. Generally speaking, with the change of the number of freeze-thaw cycles, the peak point of the theoretical curve and the peak point of the experimental data curve are in suitable agreement.

(3) In the constitutive model established in this paper, the model parameter $F_{0}$ related to the peak stress of the rock has obvious mechanical significance. As the peak stress increases, the value of $F_{0}$ gradually increases, and with the continuous increase in confining pressure, the value of $F_{0}$ also keeps increasing.

(4) The damage constitutive model established in this paper does not have specific rock type parameters. The required model parameters can be obtained through routine triaxial tests in the laboratory. It has nothing to do with lithology and can be applied to 
all kinds of hard rock. It is convenient for engineering applications and has features of wide applicability.

Author Contributions: Conceptualization, Y.C. and P.X.; methodology, P.X.; software, P.X.; validation, P.X., X.D., T.M.F.-S., R.A. and S.W.; formal analysis, P.X.; investigation, P.X.; resources, P.X.; data curation, P.X.; writing—original draft preparation, P.X.; writing—review and editing, Y.C. and P.X.; supervision, Y.C.; project administration, Y.C.; funding acquisition, Y.C. All authors have read and agreed to the published version of the manuscript.

Funding: The study was supported by "The National Natural Science Foundation of China (Project No. 10872133)". The study was supported by "Shanghai soft Science Research Key Project (Project No.18692106100").

Acknowledgments: The study was supported by "the National Natural Science Foundation of China (Project No. 10872133)". The study was supported by "Shanghai soft Science Research Key Project (Project No.18692106100)".

Conflicts of Interest: The authors declare no conflict of interest.

\section{References}

1. Zhang, Y.; Li, Q.; Zhang, F.; Xie, G. Estimates of Economic Loss of Materials Caused by Acid Deposition in China. Sustainability 2017, 9, 488. [CrossRef]

2. Feucht, L.; John, M. Effects of chemically active solutions on shearing behavior of a sandstone. Tectonophysics 1990, 175, 159-176. [CrossRef]

3. Hutchinson, A.; Johnson, J. Stone degradation due to wet deposition of pollutants. Corros. Sci. 1993, 34, 1881-1898. [CrossRef]

4. Ning, L.; Yunming, Z.; Bo, S.; Gunter, S. A chemical damage model of sandstone in acid solution. Int. J. Rock Mech. Min. Sci. 2003, 40, 243-249. [CrossRef]

5. Miao, S.; Cai, M.; Guo, Q.; Wang, P.; Liang, M. Damage effects and mechanisms in granite treated with acidic chemical solutions. Int. J. Rock Mech. Min. Sci. 2016, 88, 77-86. [CrossRef]

6. Yao, H.; Zhang, Z. Experimental Study on Influences of Chemical Solutions on Mechanical Properties of Brittle Limestone under Triaxial Compression. Phys. Numer. Simul. Geotech. Eng. 2010, 23, 149-154. [CrossRef]

7. Mohtarami, E.; Baghbanan, A.; Akbariforouz, M.; Hashemolhosseini, H.; Asadollahpour, E. Chemically dependent mechanical properties of natural andesite rock fractures. Can. Geotech. J. 2018, 55, 881-893. [CrossRef]

8. Huo, R.K.; Li, S.G.; Han, F.; Li, J. Experimental study on the characteristics of sandstone subjected to acid corrosion. IOP Conf. Ser. Earth Environ. Sci. 2018, 153, 022031. [CrossRef]

9. Li, S.; Huo, R.; Wang, B.; Ren, Z.; Ding, Y.; Qian, M.; Qiu, T. Experimental Study on Physicomechanical Properties of Sandstone under Acidic Environment. Adv. Civ. Eng. 2018, 2018, 1-15. [CrossRef]

10. Akagawa, S.; Fukuda, M. Frost heave mechanism in welded tuff. Permafr. Periglac. Process. 1991, 2, 301-309. [CrossRef]

11. Chen, T.; Yeung, M.; Mori, N. Effect of water saturation on deterioration of welded tuff due to freeze-thaw action. Cold Reg. Sci. Technol. 2004, 38, 127-136. [CrossRef]

12. Zhang, H.M.; Yang, G.S. Damage Model and Damage Mechanical Characteristics of Loaded Rock under Freeze-Thaw Conditions. Adv. Mater. Res. 2010, 168-170, 658-662. [CrossRef]

13. Bayram, F. Predicting mechanical strength loss of natural stones after freeze-thaw in cold regions. Cold Reg. Sci. Technol. 2012, 83-84, 98-102. [CrossRef]

14. Jamshidi, A.; Nikudel, M.R.; Khamehchiyan, M. Predicting the long-term durability of building stones against freeze-thaw using a decay function model. Cold Reg. Sci. Technol. 2013, 92, 29-36. [CrossRef]

15. Momeni, A.A.; Abdilor, Y.; Khanlari, G.R.; Heidari, M.; Sepahi, A. The effect of freeze-thaw cycles on physical and mechanical properties of granitoid hard rocks. Bull. Int. Assoc. Eng. Geol. 2015, 75, 1649-1656. [CrossRef]

16. Freire-Lista, D.; Fort, R.; Varas-Muriel, M. Freeze-thaw fracturing in building granites. Cold Reg. Sci. Technol. 2015, 113, 40-51. [CrossRef]

17. Yu, J.; Chen, X.; Li, H.; Zhou, J.-W.; Cai, Y.-Y. Effect of freeze-thaw cycles on mechanical properties and permeability of red sandstone under triaxial compression. J. Mt. Sci. 2015, 12, 218-231. [CrossRef]

18. Ghobadi, M.H.; Babazadeh, R. An investigation on the effect of accelerated weathering on strength and durability of Tertiary sandstones (Qazvin province, Iran). Environ. Earth Sci. 2014, 73, 4237-4250. [CrossRef]

19. Mu, J.-Q.; Pei, X.-J.; Huang, R.-Q.; Rengers, N.; Zou, X.-Q. Degradation characteristics of shear strength of joints in three rock types due to cyclic freezing and thawing. Cold Reg. Sci. Technol. 2017, 138, 91-97. [CrossRef]

20. Chen, Y.; Wang, P.; Zhang, X.; Du, X. Experimental research on mechanical properties of granite in chemical dissolution under freeze-thaw cycles. YantuGongcheng Xuebao/Chin. J. Geotech. Eng. 2014, 36, 2226-2235. [CrossRef]

21. Deng, H.W.; Dong, C.F.; Li, J.; Zhou, K.P.; Tian, W.G.; Zhang, J. Experimental Study on Sandstone Freezing-Thawing Damage Properties under Condition of Water Chemistry. Appl. Mech. Mater. 2014, 556-562, 826-832. [CrossRef] 
22. Han, T.; Shi, J.; Cao, X. Fracturing and Damage to Sandstone under Coupling Effects of Chemical Corrosion and Freeze-Thaw Cycles. Rock Mech. Rock Eng. 2016, 49, 4245-4255. [CrossRef]

23. Jamshidi, A.; Nikudel, M.R.; Khamehchiyan, M. Evaluation of the durability of Gerdoee travertine after freeze-thaw cycles in fresh water and sodium sulfate solution by decay function models. Eng. Geol. 2016, 202, 36-43. [CrossRef]

24. Gao, F.; Wang, Q.; Deng, H.; Zhang, J.; Tian, W.; Ke, B. Coupled effects of chemical environments and freeze-thaw cycles on damage characteristics of red sandstone. Bull. Int. Assoc. Eng. Geol. 2017, 76, 1481-1490. [CrossRef]

25. Deng, H.; Yu, S.; Deng, J. Damage Characteristics of Sandstone Subjected to coupled Effect of Freezing-Thawing Cycles and Acid Environment. Adv. Civ. Eng. 2018, 2018, 1-10. [CrossRef]

26. Li, S.; Huo, R.; Yoshiaki, F.; Ren, D.; Song, Z. Effect of acid-temperature-pressure on the damage characteristics of sandstone. Int. J. Rock Mech. Min. Sci. 2019, 122, 104079. [CrossRef]

27. Yu, J.; Zhang, X.; Cai, Y.; Liu, S. Microscopic damage and mechanical properties degradation of sandstone under the combined effect between water chemical corrosion and freeze-thaw cycles. Rock Soil Mech. 2019, 2, 1-10. [CrossRef]

28. Fu, H.; Zhang, J.; Huang, Z.; Shi, Y.; Chen, W. A statistical model for predicting the triaxial compressive strength of transversely isotropic rocks subjected to freeze-thaw cycling. Cold Reg. Sci. Technol. 2018, 145, 237-248. [CrossRef]

29. Huang, S.; Liu, Q.; Cheng, A.; Liu, Y. A statistical damage constitutive model under freeze-thaw and loading for rock and its engineering application. Cold Reg. Sci. Technol. 2018, 145, 142-150. [CrossRef]

30. Fang, W.; Jiang, N.; Luo, X. Establishment of damage statistical constitutive model of loaded rock and method for determining its parameters under freeze-thaw condition. Cold Reg. Sci. Technol. 2019, 160, 31-38. [CrossRef]

31. Lu, Y.; Li, X.; Chan, A. Damage constitutive model of single flaw sandstone under freeze-thaw and load. Cold Reg. Sci. Technol. 2019, 159, 20-28. [CrossRef]

32. Zhang, H.; Meng, X.; Yang, G. A study on mechanical properties and damage model of rock subjected to freeze-thaw cycles and confining pressure. Cold Reg. Sci. Technol. 2020, 174, 103056. [CrossRef]

33. Zhou, S.; Jiang, N.; Luo, X.; Fang, W.; He, X. Uniaxial Compression Fractal Damage Constitutive Model of Rock Subjected to Freezing and Thawing. Period. Polytech. Civ. Eng. 2020. [CrossRef]

34. Wang, T.; Yang, C.; Shi, X.; Ma, H.; Li, Y.; Yang, Y.; Daemen, J. Failure analysis of thick interlayer from leaching of bedded salt caverns. Int. J. Rock Mech. Min. Sci. 2015, 73, 175-183. [CrossRef]

35. Qu, D.; Li, D.; Li, X.; Luo, Y.; Xu, K. Damage evolution mechanism and constitutive model of freeze- thaw yellow sandstone in acidic environment. Cold Reg. Sci. Technol. 2018, 155, 174-183. [CrossRef]

36. Li, X.; Qu, D.; Luo, Y.; Ma, R.; Xu, K.; Wang, G. Damage evolution model of sandstone under coupled chemical solution and freeze-thaw process. Cold Reg. Sci. Technol. 2019, 162, 88-95. [CrossRef]

37. Xu, Y.; Ren, F.; Ahmed, Z.; Wang, K.; Wang, Z. Mechanical Characteristics and Damage Evolution Law of Sandstone with Prefabricated Cracks under Cyclic Loading. Arab. J. Sci. Eng. 2021, 1-13. [CrossRef]

38. Luo, X.; Zhou, S.; Huang, B.; Jiang, N.; Xiong, M. Effect of Freeze-Thaw Temperature and Number of Cycles on the Physical and Mechanical Properties of Marble. Geotech. Geol. Eng. 2021, 39, 567-582. [CrossRef]

39. Shi, L.; Liu, Y.; Meng, X.; Zhang, H. Study on Mechanical Properties and Damage Characteristics of Red Sandstone under Freeze-thaw and Load. Adv. Civ. Eng. 2021, 2021, 1-13. [CrossRef]

40. Yang, G.; Zhang, C. Rock Mass Damage and Detection; Xi'an Shaanxi Science and Technology Press: Xi'an, China, 1998.

41. Yang, G.; Xie, D.; Zhang, C. Quantitative analysis of CT number distribution of rock damage. Chin. J. Rock Mech. Eng. 1998, 17, 279-285.

42. Kachanov, L.M. Introduction to continuum damage mechanics. J. Appl. Mech. 1986, 54, 481. [CrossRef]

43. Krajcinovic, D.; Fonseka, G.U. The Continuous Damage Theory of Brittle Materials, Part 1: General Theory. J. Appl. Mech. 1981, 48, 809-815. [CrossRef]

44. Zhang, M. Experimental Study on Physical and Mechanical Properties of Red Sandstone under Freeze-Thaw Environment; Xi'an University of Science and Technology: Xi'an, China, 2015. 